\title{
Use of Idarucizumab as Dabigatran Antagonist Prior to Burr Hole Surgery for Patients with Chronic Subdural Hematoma
}

Awad $\mathrm{K}^{1 *}$, Kermer $\mathbf{P}^{\mathbf{2}}$ and Abdalla $\mathbf{Y}^{\mathbf{1}}$

${ }^{1}$ Department of Neurosurgery and Spine Surgery,

Nordwest-Krankenhaus Sanderbusch, Germany

${ }^{2}$ Department of Neurology, Nordwest-Krankenhaus

Sanderbusch, Germany

*Corresponding author: Awad K, Department of Neurosurgery and Spine Surgery, Nordwest-Krankenhaus Sanderbusch, Am Gut Sanderbusch 1, 26452 Sande, Germany

Received: December 30, 2016; Accepted: J anuary 30, 2017; Published: February 01, 2017

\section{Introduction}

The non-vitamin $\mathrm{K}$ dependent antagonists or novel oral anticoagulants (NOACs) such as dabigatran, apixaban, rivaroxaban and edoxaban become important therapeutic options in the prevention of stroke and systemic embolism in non-valvular atrial fibrillation (NVAF), treatment of deep vein thrombosis (DVT), pulmonary embolism (PE) and the prevention of their recurrence. However, they increase the risk of bleeding, in particular the intracranial- and gastrointestinal hemorrhages.

Until recently the lack of a specific NOAC antidote was a challenging limitation especially in emergency conditions that require immediate surgical intervention.

This has changed for dabigatran with the approval of idarucizumab, a humanized Fab fragment of a monoclonal antibody which binds specifically dabigatran with a very high affinity. It is indicated in dabigatran-treated patients with life-threatening or uncontrolled bleeding or those in need of urgent surgery or intervention.

There are ongoing trials worldwide but knowledge about idarucizumab application in the neurosurgical patients is scarce. We present here 3 emergency cases where idarucizumab was successfully administered before urgent trepanation surgeries for chronic subdural hematomas in patients taking dabigatran.

\section{Case 1}

A 78 year-old Caucasian male with a ventriculoperitoneal shunt (VP-shunt) due to chronic hydrocephalus was admitted on April, 5th 2016 12:56 pm to our emergency room. Over 3 days prior to admission he had developed rapid deterioration of his general condition including urinary incontinence, however without motor deficits. On admission NIHSS was 0 points, mRS 2 was points.
The patient was on dabigatran $110 \mathrm{mg}$ bid with confirmed last intake on the evening prior to admission. In addition, there was a acetylsalicylic acid prescription (100 mg once daily) as antiplatelet aggregation therapy for coronary artery disease (CAD).

Initial cranial CT-Scan (cCT) showed narrowed ventricles especially ipsilateral with acute on top of chronic subdural hematoma on the right side (maximum width of $3.2 \mathrm{~cm}$, with acute components and midline shift to the left up to $1.1 \mathrm{~cm}$ ) (Figure 1). The initial laboratory values showed activated partial thromboplastin time (aPTT) of 47.3 seconds (ULN: $42.0 \mathrm{sec}$ ). Creatinine clearance was 75 $\mathrm{ml} / \mathrm{min}$.

After a 20-minute intravenous application of $5 \mathrm{~g}$ idarucizumab (Praxbind ${ }^{\oplus}$ ) according to the prescribing information, aPTT was within normal range (29.9). A burr hole trepanation was carried out on the same day at $5 \mathrm{pm}$ to evacuate hematoma and place a JacksonPratt drain as well as retroauricular VP shunt ligation without

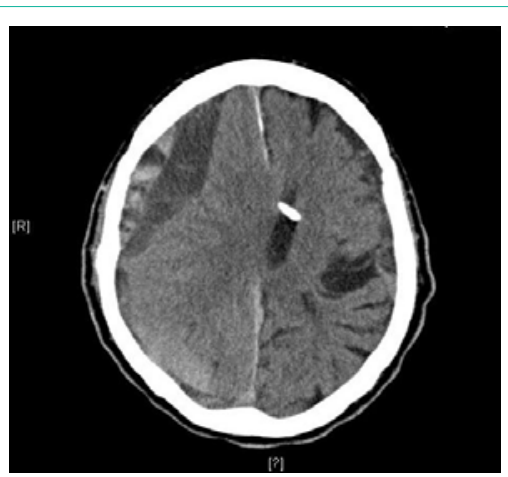

Figure 1: CT scan of patient 1 showing acute on top of chronic subdural hematoma.
Austin J Cerebrovasc Dis \& Stroke - Volume 4 Issue 1 - 2017 ISSN : 2381-9103 | www.austinpublishing group.com

Awad et al. ( All rights are reserved
Citation: Awad K, Kermer P and Abdalla Y. Use of Idarucizumab as Dabigatran Antagonist Prior to Burr Hole Surgery for Patients with Chronic Subdural Hematoma. Austin J Cerebrovasc Dis \& Stroke. 2017; 4(1): 1053. 


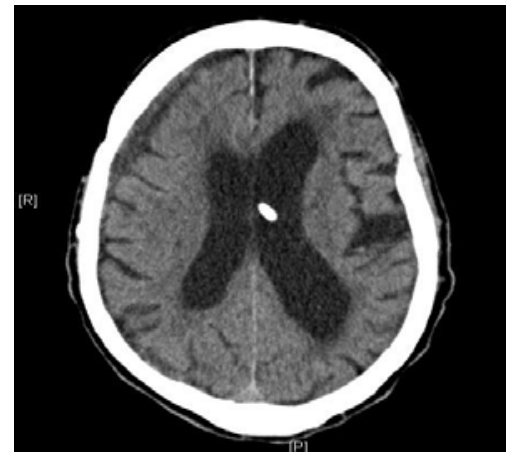

Figure 2: Postop. CT scan of patient 1 showing a significantly improved condition.

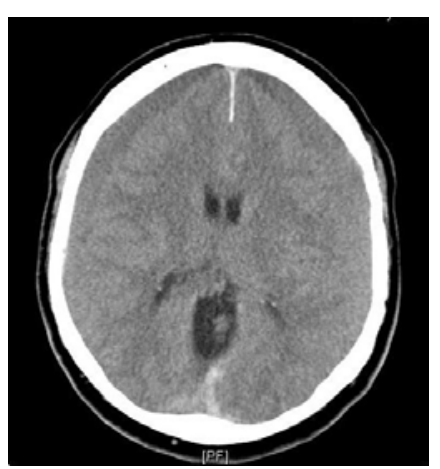

Figure 3: CT scan of patient 2 showing chronic subdural hematomas on both sides.

complications. On the third postoperative day the drain was removed and the follow-up CT scan revealed substantially reduced mass effects with almost regular expansion of the right ventricle (Figure 2).

Subsequent aPTT values on the 14, 28 and 112 post-operative days were all within normal range.

A prolonged hospital stay was attributed to severe bilateral pneumonia and pleural effusion. The patient was ICU monitored for 2 weeks and received appropriate antibiotic treatment. He was discharged into acute geriatric rehabilitation with NIHSS of 0 points.

The patient was readmitted on July 28th, 2016 to the internal medicine department because of left-sided cardiac decompensation NYHA IV. Dabigatran $110 \mathrm{mg}$ bid was restarted 4 months after surgery.

After recovery the shunt function was restored again. During follow-up in December 2016 the patient was doing well, the shunt was working properly, no recurrence.

\section{Case 2}

A 69 year-old Caucasian tourist male was admitted on Aug 6th, 2016 10:58 am to our emergency room. The patient suffered a slight head injury 4 weeks ago, since then he was complaining about increasing headache, neck pain, psychomotor delay and apathetic disorder, however, without motor deficits. On admission was NIHSS 1 points, mRS 1 was points.

Dabigatran $150 \mathrm{mg}$ bid was taken due to atrial fibrillation with

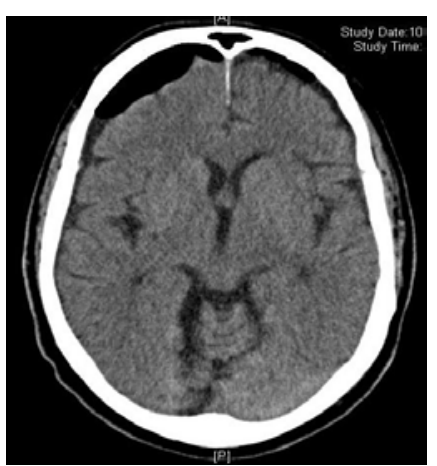

Figure 4: Postop. CT scan of patient 2 showing significantly improved findings.

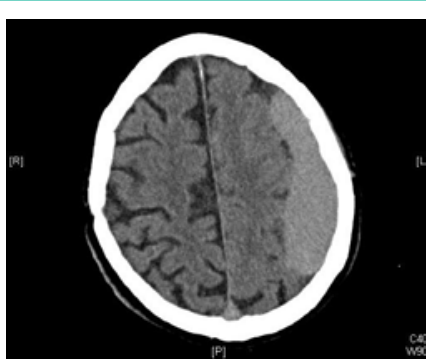

Figure 5: CT Scan of patient 3 showing chronic subdural hematoma on the left cerebral hemisphere.

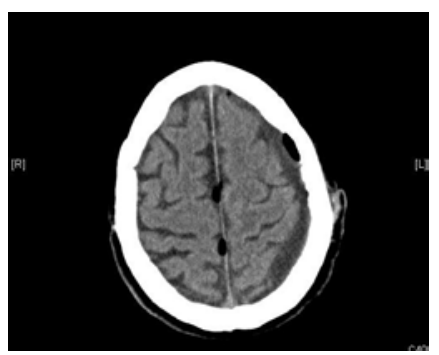

Figure 6: Postop. CT scan of patient 3 after trepanation showing substantial improvement.

last intake on the evening prior to admission.

Initial CT-Scan showed bilateral chronic subdural hematomas with mass-effect (Figure 3). Laboratory values showed aPTT of 28.8 seconds. Thrombin time (TT) was 93.3 seconds (ULN: 22.0 seconds). Creatinine clearance was $108.2 \mathrm{ml} / \mathrm{min}$.

After application of $5 \mathrm{~g}$ idarucizumab according to the prescribing information at 12:30 pm the values of aPTT ( 25.3 seconds) and TT (19.1 seconds) were normalized. Burr hole trepanations were carried out on the same day at 1:32 pm with inserting Jackson-Pratt drains on both sides without any complications. On the third postoperative day the drains were removed and the following cCT scan showed significantly improved findings (Figure 4). The patient was discharged on the seventh postoperative day with NIHSS of 0 points.

The patient returned back to his home country. Several attempts of follow-up failed. No information on anticoagulation therapy was available. 


\section{Case 3}

A 84 year-old Caucasian male was admitted on Aug $29^{\text {th }}, 2016$ $12: 13 \mathrm{pm}$ to our neurosurgical department for routine cCT scan after he had been operated on a right-sided chronic subdural hematoma 4 weeks ago. The patient, however, was without any complaints or deficits. NIHSS was 0 points, $\mathrm{mRS} 0$ points.

Dabigatran therapy $110 \mathrm{mg}$ bid due to atrial fibrillation had been restarted by the family doctor three weeks after the first trepanation. The last dose was taken on the morning of admission.

The cCT scan showed a chronic subdural hematoma on the left side with substantial mass-effect (Figure 5). Initial laboratory values showed aPTT of 43.8 seconds. TT was above 200 seconds.

After application of $5 \mathrm{~g}$ idarucizumab according to the prescribing information at $2 \mathrm{pm}$ the values of aPTT (26.2 seconds) and TT (21 seconds) were normal. A burr hole trepanation was carried out on the same day at 3:12 pm inserting a Jackson-Pratt drain on the left side without complications. On the third postoperative day the drain was removed. Follow-up cCT scan from the 5th postoperative day showed significantly improved findings (Figure 6).

Subsequent postoperative aPTT and TT values (day 3 and 14) were within normal range.

The patient was discharged 14 days after admission with NIHSS of 0 Points.

Dabigatran treatment $110 \mathrm{mg}$ bid was restarted 2 months later. During the last follow-up in November 2016, the patient was doing well, cCT was practically normal.

\section{Discussion}

For more than half a century oral anticoagulation therapy was based on vitamin $\mathrm{K}$ antagonists such as phenprocoumon and warfarin. They interfere with the synthesis of vitamin $\mathrm{K}$-dependent clotting proteins which include prothrombin (factor II) and factors VII, IX and X. Meanwhile, 4 NOACs are available for anticoagulation either targeting factor Xa (apixaban, edoxaban, rivaroxaban) or factor IIa (dabigatran). The new oral anticoagulants have been compared to warfarin for prevention of stroke and systemic embolism in patients with non-valvular atrial fibrillation in four randomized trials that enrolled 71,683 patients [1-4]. A meta-analysis of these data demonstrates high-dosed NOACs to be superior to warfarin in reduction of stroke or systemic embolism by $19 \%$, primarily driven by reduction of hemorrhagic stroke and are associated with a $10 \%$ reduction in mortality and $52 \%$ reduction of intracranial hemorrhage. However, they increase gastrointestinal bleeding by about 24\% [5].

Overall, NOACs demonstrate a favorable benefit-to-risk profile compared to warfarin in a wide spectrum of atrial fibrillation patients, including those over the age of 75 years and those with a prior history of stroke. Based on these findings, dabigatran, rivaroxaban, apixaban and edoxaban are licensed as alternatives to warfarin for stroke prevention in non-valvular atrial fibrillation.

Dabigatran which targets factor IIa (thrombin) is approved for stroke prevention in non-valvular atrial fibrillation, treatment of
DVT and PE and prevention of recurrent DVT and PE as well as the primary prevention of venous thromboembolism in total hip replacement surgery or total knee replacement surgery [6].

Although, NOACs show decreased risk for bleeding complications when compared to warfarin, until recently the lack of a specific reversal agent was a challenging limitation especially in emergency situation that required urgent surgical intervention. Prothrombin complex concentrates (PCC) are recommended for the treatment of bleeding complications under oral anticoagulation with VKAs and NOACs, however, the efficacy of this therapy has not been established in patients with intracranial hemorrhage [7-8].

A specific antidote is now available for the reversal of the anticoagulant effect of dabigatran. Idarucizumab is a humanized monoclonal antibody fragment that binds dabigatran $~ 350$ times more avidly than dabigatran binds thrombin. The standard dose of $5 \mathrm{~g}$ immediately reverses the anticoagulant activity of dabigatran [9-15].

REVERSE- $\mathrm{AD}^{\mathrm{TM}}$ is an ongoing global, Phase III, multicenter, prospective study investigating the effectiveness and safety of idarucizumab in patients treated with dabigatran in potential realworld situations (life-threatening or uncontrolled bleeding as Intracerebral hemorrhage) in which patients may require rapid emergency reversal of the anticoagulant effect of dabigatran prior to urgent medical intervention or emergency surgery. The study met its primary endpoint, achieving $100 \%$ median maximum reversal of dabigatran across all patients (95\% CI 100 to 100). Reversal was evident immediately after administrations of the first vial of idarucizumab and was complete in all but one patient. 4 and 12 hours after administration of idarucizumab, laboratory tests showed normal coagulation levels in almost $90 \%$ of patients. Normal blood clotting (homeostasis) during surgery was reported in $92 \%$ of patients that required surgery or invasive procedures [16-17].

Since the approval of idarucizumab only some cases have been reported in which idarucizumab was used prior to urgent medical interventions such as intravenous thrombolysis in ischemic stroke under dabigatran [18-21], or emergency lumbar puncture [22].

Data about the use of idarucizumab in cases of intracerebral hemorrhage under treatment with dabigatran [23] or to reduce blood loss under therapy with dabigatran in trauma [24] are very limited.

In our case series we applied idarucizumab in three patients with chronic subdural hemorrhage. All patients were on dabigatran for prevention of vascular thromboembolism associated with atrial fibrillation. Idarucizumab effectively reversed the anticoagulatory effect of dabigatran as indicated by normalized values for aPTT and TT immediately after idarucizumab application. This enabled us to carry out a burr hole trepanation without any complication or increased bleeding throughout the operation or afterwards.

\section{Conclusion}

From our small case series we conclude that idarucizumab can be used safely and effectively as specific reversal agent of dabigatran prior to urgent surgical interventions such as burr hole trepanation in chronic subdural hematoma. However, further data from controlled trials and patient registries are needed to confirm our results. 


\section{References}

1. Connolly SJ, Ezekowitz MD, Yusuf S, Eikelboom J, Oldgren J, Parekh A, et al. Dabigatran versus warfarin in patients with atrial fibrillation. N Engl J Med. 2009; 361: 1139-1151.

2. Patel MR, Mahaffey KW, Garg J, Pan G, Singer DE, Hacke W, et al Rivaroxaban versus warfarin in nonvalvular atrial fibrillation. N Engl J Med. 2011; 365: 883-891.

3. Granger CB, Alexander JH, McMurray JJ, Lopes RD, Hylek EM, Hanna M, et al. Apixaban versus warfarin in patients with atrial fibrillation. N Engl J Med. 2011; 365: 981-992.

4. Giugliano RP, Ruff CT, Braunwald E, Murphy SA, Wiviott SD, Halperin JL, et al. Edoxaban versus warfarin in patients with atrial fibrillation. N Engl J Med. 2013; 369: 2093-2104.

5. Ruff CT, Giugliano RP, Braunwald E, Hoffman EB, Deenadayalu N, Ezekowitz $M D$, et al. Comparison of the efficacy and safety of new oral anticoagulants with warfarin in patients with atrial fibrillation: a meta-analysis of randomised trials. Lancet. 2014; 383: 955-962.

6. Pradaxa Summary of Product Characteristics 2015. Boehringer Ingelheim

7. Heidbuchel H, Verhamme P, Alings M, Antz M, Diener HC, Hacke W, et al Updated European Heart Rhythm Association practical guide on the use of non-vitamin-K antagonist anticoagulants in patients with non-valvular atria fibrillation: Executive summary. Eur Heart J. 2016.

8. Frontera JA, Lewin JJ, Rabinstein AA, Aisiku IP, Alexandrov AW, Cook AM7, et al. Guideline for Reversal of antithrombotics in Intracranial Hemorrhage: Executive Summary. A Statement for Healthcare Professionals from the neurocritical Care Society and the Society of Critical Care Medicine. Crit Care Med. 2016; 44: 2251-2257.

9. Glund S, Stangier J, Schmohl M, Gansser D, Norris S, Ryn Jv, et al. Safety, tolerability, and efficacy of idarucizumab for the reversal of the anticoagulant effect of dabigatran in healthy male volunteers: a randomised, placebocontrolled, double-blind phase 1 trial. Lancet. 2015; 386: 680-690.

10. Pollack CV, Reilly PA, Eikelboom J, Glund S, Verhamme P, Richard A, et al Idarucizumab for Dabigatran Reversal. N Engl J Med. 2015; 373: 511-520.

11. Finks SW, Rogers KC. Idarucizumab (Praxbind $®$ ): The first reversal agent for a direct oral anticoagulant. Am J Med. 2016.

12. Sié P. Spotlight on idarucizumab and its potential for the reversal of anticoagulant effects of dabigatran. Drug Des Devel Ther. 2016; 10: 1683 1689 .
13. Hu TY, Vaidya VR, Asirvatham SJ. Reversing anticoagulant effects of nove oral anticoagulants: role of ciraparantag, andexanet alfa, and idarucizumab. Vasc Health Risk Manag. 2016; 12: 35-44.

14. Schmohl M, Glund S, Harada A, Imazu S, Smet MD, Moschetti V, et al. Idarucizumab does not have procoagulant effects: Assessment of thrombosis biomarkers in healthy volunteers. Thromb Haemost. 2016

15. Glund S, Stangier J, van Ryn J, Schmohl M2, Moschetti V3, Haazen W4, et al. Effect of age and renal function on Idarucizumab pharmacokinetics and Idarucizumab-mediated reversal of Dabigatran anticoagulant activity in a randomized, double-blind, crossover phase lb study. Clin Pharmacokinet. 2017. 56: 41-54.

16. Pollack CV Jr, Reilly PA, Bernstein R, Dubiel R, Eikelboom J, Glund S, et al. Design and rationale for RE-VERSE AD: A phase 3 study of idarucizumab, specific reversal agent for dabigatran. Thromb Haemost. 2015; 114: 198-205.

17. Pollack CV Jr, Reilly PA, Eikelboom J, Glund S, Verhamme P, Bernstein RA et al Idarucizumab for Dabigatran Reversal. N Engl J Med. 2015; 373: 511 520

18. Gawehn A, Ayari Y, Heuschkel C, Kaste M, Kermer P. Successful thrombolysis with recombinant tissue plasminogen activator after antagonizing dabigatran by idarucizumab: a case report. J Med Case Rep. 2016; 10: 269.

19. Mutzenbach JS, Pikija S, Otto F, Halwachs U, Weymayr F, Sellner J, et al Intravenous thrombolysis in acute ischemic stroke after dabigatran reversal with idarucizumab - a case report. Ann Clin Transl Neurol. 2016; 3: 889-892.

20. Kafke W, Kraft P. Intravenous thrombolysis after reversal of Dabigatran by Idarucizumab: A Case Report. Case Rep Neurol. 2016; 8: 140-144.

21. Berrouschot J, Stoll A, Hogh T, Eschenfelder CC2, et al. Intravenous thrombolysis with recombinant tissue-type plasminogen activator in a stroke patient receiving Dabigatran anticoagulant after antagonisation with Idarucizumab. Stroke. 2016; 47: 1936-1938.

22. Braemswig TB, Eschenfelder $\mathrm{CC}$, Nolte $\mathrm{CH}$. Emergency lumbar puncture in a patient receiving dabigatran after antagonisation with idarucizumab - A case report. Am J Emerg Med. 2016; pii: S0735-6757(16)30785-9.

23. Held V, Eisele P, Eschenfelder CC2, Szabo K, et al. Idarucizumab as Antidote to Intracerebral Hemorrhage under Treatment with Dabigatran. Case Rep Neurol. 2016; 8: 224-228.

24. Honickel M, Braunschweig T, Van Ryn J, Rossaint R, Grottke O. Efficacy of idarucizumab, prothrombin complex concentrate (PCC) and activated PCC to reverse the anticoagulatory potential of dabigatran in a porcine polytrauma model. Crit Care. 2015; 19: P351.
Austin J Cerebrovasc Dis \& Stroke - Volume 4 Issue 1 - 2017 ISSN : 2381-9103 | www.austinpublishinggroup.com Awad et al. (C) All rights are reserved
Citation: Awad K, Kermer P and Abdalla Y. Use of Idarucizumab as Dabigatran Antagonist Prior to Burr Hole Surgery for Patients with Chronic Subdural Hematoma. Austin J Cerebrovasc Dis \& Stroke. 2017; 4(1): 1053. 